\title{
The Investigation and Analysis of Self-esteem and Coping Style of High Vocational Students*
}

\author{
Zhili $\mathrm{Bi}^{1}$, Tongjun Wang ${ }^{2}$, Shubai Chen ${ }^{3}$ \\ ${ }^{1)}$ Nursing School, Binzhou Polytechnic, Binzhou, Shandong, China (beelili@ 126.com) \\ ${ }^{2)}$ Department of Student Affairs, Binzhou Polytechnic, Binzhou, Shandong, China (wtongjun2008@163.com) \\ ${ }^{3)}$ Nursing School, Binzhou Polytechnic, Binzhou, Shandong, China (shubai520@126.com)
}

\begin{abstract}
We adopt the Self-esteem Scale (SES) and the Simplified Coping Style Questionnaire, to make a random investigation among the Binzhou Polytechnic students in 6 professionals of grade 2012. As a result, the Self-esteem Scale score was 32.59 \pm 3.40 . Positive coping style score was $2.14 \pm 0.38$, negative coping style score was $1.29 \pm 0.48$. And we distinguished the students' gender, they from the city or the countryside, and their family economic status, comparison the survey results. We analysed the correlation of self-esteem and coping styles, and organized the commonly used coping styles for high vocational students. The purpose of this study is to provide guidance for the mental health education of high vocational students.
\end{abstract}

Keywords—high vocational students, Self-esteem Scale, coping style, mental health education

\section{高职生自尊与应对方式情况调查与分析}

\author{
毕智丽 $^{1}$ 王同军 $^{2}$ 陈树柏 $^{1}$ \\ 1) 滨州职业学院护理学院, 滨州, 山东, 中国 \\ 2) 滨州职业学院学生工作处, 滨州, 山东, 中国
}

摘 要 选用自尊量表 (SES) 和简易应对方式问卷, 对滨州职业学院 2012 级 6 个专业的学生进行随机调查, 结果自尊量表得分 $32.59 \pm 3.40$, 积极应对方式得分 $2.14 \pm 0.38$, 消极应对方式得分 $1.29 \pm 0.48$, 区分学生性别、生源地性质和家庭经济状况, 对调查结果进 行比较, 以及自尊与应对方式的相关性分析, 并对高职生常用应对方式进行了整理, 为高职生心理健康教育提供指导。

关键词 高职生, 自尊量表, 应对方式, 心理健康教育

1. 前言

滨州职业学院是国家骨干高等职业院校, 重视学生管 理与教育的各项工作, 特别在学生心理健康教育、贫困生 认定与奖助学金评定等方面的工作中, 制度规范、程序合 理、活动多样, 深受学生的认可与拥护。如何面向贫困生 开展有针对性的心理健康教育, 是关注校园内的弱势群体, 支持学生健康成才的重要方面。

我们从 2012 年开始进行小规模的贫困生自尊与应对方 式调查 $^{[1]}$, 至 2013 年, 逐步将调查扩大到了更多专业、更
多贫困生和非贫困生, 以期将调查结果、现象解读、需求 分析运用到实际工作中, 对心理健康教育工作的开展提供 指导。

\section{2. 研究对象与方法}

为保持研究的延续性和调查结果的可比性, 继续选用 前期调查使用的自尊量表 (SES) 和简易应对方式问卷。滨 职 2013 年度贫困生认定与国家奖助学金评定工作结束后, 面向护理、园林技术、轮机技术、食品、制药、工商企业 管理等 6 个专业的 12 级(高职二年级)学生(年龄 $20.08 \pm 0.63$

\footnotetext{
*山东省高等学校学生教育与管理研究项目立项课题 (编号: 2013C032)

作者简介: 毕智丽 (1979- ), 女, 河北沧州人, 讲师, 硕研。滨州职业学院护理学院辅导员, 国家二级心理咨询师。

电话: 13589738725, 地址: 滨州市滨州职业学院护理学院, 邮编: 256603
} 
岁), 发放问卷 649 份, 回收有效问卷 646 份, 有效比例 $99.54 \%$ 。其中男生 67 人, 占 $10.37 \%$,女生 579 人, 占 $89.63 \%$; 城镇生源 144 人, 占 $22.29 \%$, 农村生源 502 人, 占 $77.71 \%$; 非贫困生 446 人, 占 $69.04 \%$, 贫困生 200 人, 占 $30.96 \%$ 。 200 名被认定为贫困生的学生, 是按照国家和学校相关规 定, 由各行政班级民主选举的评议小组认定的, 其中因名 额限制未受资助的 54 人 (27.00\%), 获得国家励志奖学金 (5000 元) 的 47 人 (23.50\%), 获得国家一档助学金 (2000 元/年) 的 22 人 $(11.00 \%)$, 二档 $(3000$ 元/年 $) 40$ 人 $(20.00 \%)$, 三档 $(4000$ 元/年) 37 人 $(18.50 \%)$ 。

自尊量表, Rosenberg 编制。本研究根据相关文献, 将 第 8 题改为正向记分 ${ }^{[2]}$ 。简易应对方式问卷分为积极应对和 消极应对 2 个分量表, 分别计分, 并计算应对倾向=积极应 对标准分-消极应对标准分, 根据张育坤和解亚宁的研究结 果, 样本的积极应对维度均分为 1.78 , 标准差为 0.52 ; 消 极应对维度均分为 1.59 , 标准差为 $0.66^{[3]}$ 。

\section{3. 结果与分析}

\section{1 数据统计}

分别计算全体调查对象的自尊量表和简易应对方式问 卷得分, 并进行统计分析, 比较不同性别、生源地性质和 家庭经济状况高职生的得分情况, 结果如表 1 。

表 1 高职生自尊量表和简易应对方式问卷得分统计

\begin{tabular}{|c|c|c|c|}
\hline & 自尊量表得分 & $\begin{array}{c}\text { 积极应对 } \\
\text { 维度得分 }\end{array}$ & $\begin{array}{c}\text { 消极应对 } \\
\text { 维度得分 }\end{array}$ \\
\hline 总体 & $32.59 \pm 3.40$ & $2.14 \pm 0.38$ & $1.29 \pm 0.48$ \\
\hline 男 & $32.18 \pm 3.55$ & $2.08 \pm 0.40$ & $1.49 \pm 0.56$ \\
\hline 女 & $32.64 \pm 3.38$ & $2.14 \pm 0.38$ & $1.26 \pm 0.47$ \\
\hline $\mathrm{t}$ 值 & -0.854 & -1.008 & 2.886 \\
\hline $\mathrm{P}$ & 0.197 & 0.157 & 0.002 \\
\hline 城镇 & $32.69 \pm 3.49$ & $2.14 \pm 0.41$ & $1.38 \pm 0.50$ \\
\hline 农村 & $32.56 \pm 3.38$ & $2.13 \pm 0.37$ & $1.26 \pm 0.47$ \\
\hline $\mathrm{t}$ 值 & 0.313 & 0.252 & 2.126 \\
\hline $\mathrm{P}$ & 0.377 & 0.400 & 0.017 \\
\hline 非贫困生 & $32.61 \pm 3.52$ & $2.14 \pm 0.39$ & $1.33 \pm 0.48$ \\
\hline 贫困生 & $32.55 \pm 3.13$ & $2.13 \pm 0.37$ & $1.18 \pm 0.47$ \\
\hline $\mathrm{t}$ 值 & 0.201 & 0.237 & 2.926 \\
\hline $\mathrm{P}$ & 0.421 & 0.406 & 0.002 \\
\hline
\end{tabular}

结果显示滨职高职学生的自尊水平整体较高[2,3], 对
不同性别、生源地性质、家庭经济状况的高职学生, 在自 尊、积极应对和消极应对 3 个方面分别进行比较。结果自 尊量表得分和积极应对维度得分均呈现 $p>0.05$ 的情况, 无 显著差异, 提示性别、生源地性质和家庭经济状况对高职 生自尊和积极应对方式的选择无明显影响。

然而在消极应对方面情况大不相同, 不同性别、家庭 经济状况比较, $\mathrm{p}$ 均 $<0.01$, 即差异极显著, 不同生源地性 质比较 $0.01<\mathrm{p}<0.05$, 也呈显著差异。这说明男生比女生 更多地选择消极应对方式, 此结果与梁军林等 ${ }^{[4]}$ 的研究结果 相反; 城镇生源的学生比农村生源的学生更多地选择消极 应对方式, 非贫困生比贫困生更多地选择消极应对方式, 这与马利军等的研究结果不同 ${ }^{[5]}$ 。

\section{2 高职生应对方式分析}

\section{2 .1 高职生常用应对方式}

高职生常用应对方式的前 10 位如表 2 所示, 前 9 位均 为积极应对方式, 仅第 10 位属于消极应对方式。

表 2 高职生常用应对方式前 10 位

\begin{tabular}{|l|c|}
\hline \multicolumn{1}{|c|}{ 应对方式 } & 得分 \\
\hline 尽量看到事物好的一面 & $2.40 \pm 0.66$ \\
\hline 坚持自己的理想, 为自己想得到的斗争 & $2.32 \pm 0.68$ \\
\hline 改变自己的想法, 重新发现生活中什么重要 & $2.27 \pm 0.66$ \\
\hline 与人交谈, 倾诉内心烦恼 & $2.25 \pm 0.68$ \\
\hline 找出几种不同的解决问题的方法 & $2.24 \pm 0.62$ \\
\hline 尽量克制自己的失望、悔恨、悲伤和愤怒 & $2.16 \pm 0.64$ \\
\hline 向亲戚朋友或同学寻求建议 & $2.15 \pm 0.67$ \\
\hline 寻求业余爱好, 积极参加文体活动 & $2.07 \pm 0.68$ \\
\hline 改变原来的一些做法或自己的一些问题 & $2.05 \pm 0.57$ \\
\hline 自己安慰自己 $(\mathrm{N})$ & $2.04 \pm 0.68$ \\
\hline
\end{tabular}

对不同性别、生源地性质、家庭经济状况高职生常用 应对方式前 10 位的分布进行比较, 序位变化都在积极应对 各方式之间。其中不同性别高职学生应对方式前 10 位差别 较大, 主要是男生的选择较大地偏离了平均状况, 差别最 大的 3 项为: (1) “与人交谈, 倾诉内心烦恼”项得分 $2.04 \pm 0.71$, 与女生 (2.28 \pm 0.67$)$ 比较, $\mathrm{p}<0.01$, 差异极显著; (2)“向 亲戚朋友或同学寻求建议” 项得分 $1.93 \pm 0.61$, 与女生 (2.18 \pm 0.68$)$ 比较, $\mathrm{p}<0.01$, 差异极显著; (3) “自己安慰 自己”项得分 $2.22 \pm 0.67$, 与女生 $(2.02 \pm 0.68)$ 比较, 0.01 $<\mathrm{p}<0.05$, 差异显著。此结果体现了在沟通的主动性方面 存在着性别差异。 
表 3 分别对高职生选择“经常采取”的积极和消极应对 方式的人数进行了统计。

\subsection{2 高职生应对倾向}

表 4 是高职生积极或消极应对倾向的人数、所占比例, 及不同性别、生源地性质、家庭经济状况高职生积极或消 极应对倾向的人数, 及在各自群体中所占的比例。结果显 示, 更大比例的高职女生比男生能够选择积极方式应对应 激状态, 农村生源的高职生选择积极应对方式的比例更大; 贫困生选择积极应对方式的比例比非贫困生大。这都与前 述在消极应对方式得分上的差异有关。

表 3 高职生经常采取的积极和消极应对方式

\begin{tabular}{|l|c|c|}
\hline \multicolumn{1}{|c|}{ 应对方式条目 } & $\begin{array}{c}\text { 选择 } \\
\text { 人次 }\end{array}$ & 比例 \\
\hline 积极应对方式 & & \\
\hline 尽量看到事物好的一面 & 357 & $55.26 \%$ \\
\hline 坚持自己的理想, 为自己想得到的斗争 & 322 & $49.85 \%$ \\
\hline 改变自己的想法,重新发现生活中什么重要 & 295 & $45.67 \%$ \\
\hline 与人交谈, 倾诉内心烦恼 & 292 & $45.20 \%$ \\
\hline 找出几种不同的解决问题的方法 & 263 & $40.71 \%$ \\
\hline 消极应对方式 & & \\
\hline 自己安慰自己 & 229 & $35.45 \%$ \\
\hline 试图休息或休假, 暂时把问题 (烦恼) 抛开 & 196 & $30.34 \%$ \\
\hline 接受现实, 因为没有其它办法 & 81 & $12.54 \%$ \\
\hline 幻想可能会发生某种奇迹改变现状 & 70 & $10.84 \%$ \\
\hline 试图忘记整个事情 & 69 & $10.68 \%$ \\
\hline
\end{tabular}

表 4 高职生应对倾向

\begin{tabular}{|c|c|c|c|c|}
\hline \multirow{2}{*}{} & \multicolumn{2}{|c|}{ 积极应对倾向 } & \multicolumn{2}{c|}{ 消极应对倾向 } \\
\cline { 2 - 5 } & 人数 & 比例 & 人数 & 比例 \\
\hline 总 & 526 & $81.42 \%$ & 120 & $18.58 \%$ \\
\hline 男 & 47 & $70.15 \%$ & 20 & $29.85 \%$ \\
\hline 女 & 479 & $82.73 \%$ & 100 & $17.27 \%$ \\
\hline 城镇 & 114 & $79.17 \%$ & 30 & $20.83 \%$ \\
\hline 农村 & 412 & $82.07 \%$ & 90 & $17.93 \%$ \\
\hline 非贫困生 & 355 & $79.60 \%$ & 91 & $20.40 \%$ \\
\hline 贫困生 & 171 & $85.50 \%$ & 29 & $14.50 \%$ \\
\hline
\end{tabular}

\section{3 高职生自尊与应对方式的相关研究}

将高职生按其自尊量表的得分情况分出 2 个极端组, 比平均分（32.59）低 1 个标准差 (3.40) 以上, 即量表得 分小于等于 29 分的为低分组; 高 1 个标准差以上, 即量表 得分大于等于 36 分的为高分组。分别统计高分组和低分组 中分布的不同性别、生源地性质、家庭经济状况高职生人 数, 及其在各自类别中所占的比例, 结果如表 5 。

将自尊高分组与低分组简易应对方式量表中的积极应 对方式和消极应对方式得分进行比较, 结果均为 $\mathrm{p}<0.01$, 即差异极显著。积极应对方式, 自尊高分组 $2.39 \pm 0.33$, 显 著高于自尊低分组 $1.92 \pm 0.40$; 而消极应对方式相反, 自尊 低分组 $1.48 \pm 0.44$, 显著高于自尊高分组 $1.30 \pm 0.56$, 这与马 利军等运用肖计划《应对方式问卷》所做调研结论一致 ${ }^{[5]}$ 。 说明高职生对应对方式的选择与其自尊水平存在正向相 关。

表 5 自尊高分组与低分组各类学生比例

\begin{tabular}{|c|c|c|c|c|}
\hline \multirow{2}{*}{} & \multicolumn{2}{|c|}{ 高分组 } & \multicolumn{2}{c|}{ 低分组 } \\
\cline { 2 - 5 } & 人数 & 比例 & 人数 & 比例 \\
\hline 总 & 161 & $24.92 \%$ & 137 & $21.21 \%$ \\
\hline 男 & 16 & $23.88 \%$ & 14 & $20.90 \%$ \\
\hline 女 & 145 & $25.04 \%$ & 123 & $21.24 \%$ \\
\hline 城镇 & 37 & $25.69 \%$ & 29 & $20.14 \%$ \\
\hline 农村 & 124 & $24.70 \%$ & 108 & $21.51 \%$ \\
\hline 非贫困生 & 115 & $25.78 \%$ & 96 & $21.52 \%$ \\
\hline 贫困生 & 46 & $23.00 \%$ & 41 & $20.50 \%$ \\
\hline
\end{tabular}

\section{4. 讨论}

本研究显示我校高职生自尊与应对方式整体情况较 好。但仍存在一些需要关注的问题, 如城镇生源的学生比 农村生源的学生、非贫困生比贫困生更多选择消极应对方 式, 这可能与家庭教育、社会环境、成长经历等有关, 也 有可能是因为能够得到评定和资助的学生, 比实际存在的 贫困生少, 未能得到认定、资助的学生心态因而受到了影 响, 这需要进一步区分, 并在心理健康教育中, 向此类群 体开展针对性工作; 男高职生存在较多问题, 消极应对得 分高、消极应对倾向比例大、自尊高分比例小, 以及更多 选择自己安慰自己, 而非主动与人交流, 这可能与样本较 小有关, 也可能是因为某些被调查专业性别比例不均衡, 男生偏少有关, 他们长时间在以女生为主的环境中学习、 生活, 心理上出现了一些不良变化, 因此特别需要在这样 的专业中, 关注男高职生的心理健康发展。 


\section{参考文献(References)}

[1] Zhili Bi, "Correlation study about the self-esteem of impoverished high vocational nursing students and their coping styles," 2014 4th International Conference on Applied Social Science (ICASS 2014).

[2] Xiangqian Han, Bo Jiang and Jiayan Tang, "Self-esteem scale used in the process of problems and suggestions," Chinese Journal of Behavioral Medical and Brain Science, vol. 14, no. 8, pp. 763, 2005.
[3] Xiaoyang Dai, etc, Common psychological assessment handbook. People's Military Medical Press, vol. 7, pp. 251-253, 2010.

[4] Junlin Liang, Dongshi Li, Zhenni Liu, etc, "Correlation between defense style or coping style and mental health in high school students," Chinese Mental Health Journal, vol. 13, no. 3, pp. 146-147, 1999.

[5] Lijun Ma and Huiping Tan, "Correlation between students' self-esteem and coping style of medical college poverty," Soft Science of Health, vol. 23, no. 6, pp. 627-629, 2009. 